\section{Under-5 mortality and the contribution of congenital disorders in South Africa}

To the Editor: The article 'Child mortality in South Africa: Fewer deaths but better data are needed, ${ }^{[1]}$ which appeared in the March 2018 SAMJ Maternal and Child Health Supplement, reviews nationally representative mortality data and the causes of death in children under 5 years of age in South Africa (SA). Two different terms are used synonymously without definition in this article - 'congenital disorders' and 'congenital abnormalities'. By definition, congenital disorders (CDs) are abnormalities in structure or function present from birth, including inborn errors of metabolism. ${ }^{[2]}$ Congenital abnormalities (often used interchangeably with 'congenital anomalies') are a subset of CDs, previously defined in the literature as obvious structural abnormalities as categorised in Chapter XVII: 'Congenital malformations, deformations and chromosomal abnormalities' in the International Statistical Classification of Diseases and Related Health Problems (ICD-10) which excludes a third of CDs included elsewhere in the ICD-10..$^{[3-6]}$

Congenital abnormalities are also referred to by Bamford et al. ${ }^{[1]}$ as a separate entity from non-communicable diseases (NCDs), contrary to the World Health Organization (WHO) definition of CDs as an NCD and the concept of CDs as being the first NCD experienced in life. ${ }^{[7-10]}$ Excluding CDs from this disease category has implications for achieving the Sustainable Development Goal (SDG) 3 target of reducing premature mortality from NCDs by one-third. ${ }^{[11]}$

While the abovementioned article highlights potential underestimates in the vital registration data of deaths due to HIV infection and malnutrition, this consideration is not given for CD diagnoses omitted from death certificates. ${ }^{[1]}$ This is despite the parallel between these diagnoses in being omitted as the correct recorded cause of death (contributory or otherwise) due to reluctance with regard to HIV cases and non-/misdiagnosis of CDs. The Child Problem Identification Programme (Child PIP), in particular, has cited a lack of clinicians necessary to make accurate diagnoses as a limitation in the cause of death categorisation. ${ }^{[12,13]}$

The recommendation by Bamford et al. ${ }^{[1]}$ to scale up interventions to reduce deaths from emerging causes of under-5 child death includes congenital abnormalities, which have risen from 3.9\% in 2011 as a proportional cause of death to $5.9 \%$ in 2015. Combined with the simultaneous reduction in infectious diseases, e.g. diarrhoea and pneumonia, this is indicative of the ongoing positive epidemiological transition in SA. ${ }^{[9,14]}$ Following the trend of high-income countries where CDs account for up to $28 \%$ of under-5 deaths, ${ }^{[15]}$ it is imperative that these interventions include relevant medical genetic services for the care and prevention of those affected by and at risk of CDs. With up to $70 \%$ of CDs potentially prevented or cured and subsequent disability ameliorated, the potential impact of addressing CDs cannot be ignored owing to the sizeable proportion of preventable child deaths. ${ }^{[16-19]}$ This makes the prioritisation of CDs key to reducing preventable child and neonatal deaths and to attaining the SDG targets. ${ }^{[11]}$

For the quality of data in death notification forms to improve, capacity must be increased to ensure the accurate diagnosis of CDs as the cause of death for both neonatal and child deaths. With tertiary-level genetic services available in only 3 of the 9 provinces and national surveillance grossly underreporting CDs, there is much room for improvement. ${ }^{[20,21]}$ It is anticipated that the restructuring of disease surveillance, including CDs, under the National Public Health Institute of South Africa (NAPHISA) will rectify some of these issues, but more targeted action is required. ${ }^{[22]}$
To achieve the SDG 3 target to reduce the SA under-5 mortality rate from 37 - 40 deaths per 1000 live births to the required target of $<25$ per 1000 , a $37 \%$ reduction is required. ${ }^{[1,11]}$ Previously unprioritised health issues, including CDs, must now be addressed for this target to be reached. The literature is clear on the role of comprehensive medical genetic services in significantly reducing child mortality. With an infant mortality rate of 27 - 33 deaths per 1000 live births, SA is long past the point of 40 infant deaths per 1000 live births, when countries should implement these services. ${ }^{[1,8,10,16,23]}$ To meet SDG 3 by 2030, the role of CDs in neonatal, infant and child mortality must be comprehensively addressed as a priority in SA.

Author contributions. All authors were involved in the conceptualisation of this letter and provided input and technical contributions to the draft produced by the principal author (HLM). All authors signed off on the final version before submission.

Funding. Thanks to the School of Clinical Medicine, University of KwaZulu-Natal, Durban, SA, for their ongoing support of this research via a post-doctoral research scholarship.

\section{Helen L Malherbe}

School of Clinical Medicine, College of Health Sciences, University of KwaZulu-Natal, Durban, South Africa

helen@hmconsult.co.za

\section{Arnold L Christianson}

Wits Centre for Ethics (WiCE), Department of Philosophy, Faculty of Humanities, University of the Witwatersrand, Johannesburg, South Africa

\section{David Woods}

Newborn Care, School of Child and Adolescent Health, Faculty of Health Sciences, University of Cape Town, South Africa

\section{Colleen Aldous}

Emerging Academics Research Support, School of Clinical Medicine, College of Health Sciences, University of KwaZulu-Natal, Durban, South Africa

1. Bamford L, McKerrow N, Barron P, Aung Y. Child mortality in South Africa: Fewer deaths, bu better data are needed. S Afr Med J 2018;108(Suppl 1):S25-S32. https://doi.org/10.7196/samj.2017. v108i3b. 12779

2. World Health Organization. Management of Birth Defects and Haemoglobin Disorders. Report of Joint WHO-March of Dimes Meeting. Geneva, Switzerland, 17 - 19 May 2006. Geneva: WHO, 2006:27.

Reid AE, Hendricks MK, Groenewald P, Bradshaw D. Where do children die and what are the causes? Under- 5 deaths in the Metro West geographical service area of the Western Cape, South Africa, 2011. S Afr Med J 2016;106(4):359-364. https://doi.org/10.7196/samj.2016.v106i4.10521

4. Pillay-van Wyk V, Msemburi W, Laubscher R, et al. Mortality trends and differentials in South Africa from 1997 to 2012. Second National Burden of Disease Study Lancet Glob Heath

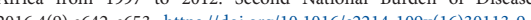

5. World Health Organization. International Statistical Classification of Diseases and Related Health Problems. 10th revision. Geneva: WHO, 1992.

6. Bradshaw D, Groenewald P, Laubscher R, et al. Initial Burden of Disease Estimates for South Africa, 2000. Cape Town: Medical Research Council, 2003:84.

World Health Organization. Global Action Plan for the Prevention and Control of Noncommunicable Diseases 2013 - 2020. Geneva: WHO, 2013:55.

8. World Health Organization. Guidelines for the Development of National Programmes for Monitoring Birth Defects. Geneva: WHO, 1993:33.

9. Malherbe H, Christianson A, Aldous C. Need for services for the care and prevention of congenita disorders in South Africa as the country's epidemiological transition evolves. S Afr Med 2015;105(3):186-188. https://doi.org/10.7196/samj. 9136

0. Christianson A, Modell B. Medical genetics in developing countries. Ann Rev Genomics Hum Genet 2004;5:219-265. https://doi.org/10.1146/annurev.genom.5.061903.175935

11. United Nations. Sustainable Development Goal 3: Ensure Healthy Lives and Promote Well-being for All and at All Ages. Geneva: UN, 2015.

12. Patrick M, Stephen C. Saving children: 2005. A survey of child healthcare in South Africa. Child PIP and MRC Unit for Maternal and Infant Health Care Strategies, 2005. http://www.childpip.org.za/ documents/report_saving_children_2005.pdf (accessed 12 May 2018).

13. Patrick M, Malherbe H, Stephen C, Woods D, Aldous C. Congenital disorders in South Africa: A review of Child PIP mortality data 2005 - 2017. S Afr Med J 2018 (in press).

14. Omran AR. The epidemiologic transition: A theory of the epidemiology of population change. Milbank Memorial Fund Quarterly 1971;49(4):509-538. https://doi.org/10.2307/3349375 
15. World Health Organization. World Health Statistics 2015. Geneva: WHO, 2015:164.

16. Alwan A, Modell B. Recommendations for introducing genetics services in developing countries. Nat Rev Genet 2003;4(1):61-68. https://doi.org/10.1038/nrg978

17. World Health Organization. Control of Hereditary Diseases: Report of a WHO Scientific Group 1993 Geneva: WHO, 1996:92

18. Czeizel A, Intôdy Z, Modell B. What proportion of congenital abnormalities can be prevented? BM] 1993;306:499-503. https://doi.org/10.1136/bmj.306.6876.499

19. Whitt KJ, Hughes M, Hopkins EBS, Maradiegue A. The gene pool: The ethics of genetics in primary care. Annu Rev Nurs Res 2016;34(1):119-154. https://doi.org/10.1891/0739-6686.34.119

20. Lebese L, Aldous C, Malherbe H. South African congenital disorders data, 2006 - 2014. S Afr Med J 2016;106(10):992-995, https://doi.org/10.7196/samj.2016.v106i10.11314
21. Malherbe H, Aldous C, Woods D, Christianson A. The contribution of congenital disorders to child mortality in South Africa. In: Padarath A, King J, Mackie E, Casciola J, eds. South African Health Review 2016. 19th ed. Durban: Health Systems Trust, 2016:137-152.

22. South Africa. National Public Health Insitute of South Africa Bill, No. B16-2017, 2017.

23. Modell B, Kuliev A. The history of community genetics: The contribution of the haemoglobin disorders. Commun Genet 1998:1:3-11. https://doi.org/10.1159/000016129

S Afr Med J 2018;108(6):447-448. DOI:10.7196/SAMJ.2018.v108i6.13331 